\title{
ANALISIS AVAILABILITAS DAN RELIABILITAS MULTI-MASTER DATABASE SERVER DENGAN STATE SNAPSHOT TRANSFERS (SST) JENIS RSYNC PADA MARIADB GALERA CLUSTER
}

\author{
Mahendra Data', Gilang Ramadhan², Kasyful Amron ${ }^{3}$ \\ 1,2,3 Fakultas Ilmu Komputer Universitas Brawijaya \\ Email: ${ }^{1}$ mahendra.data@ub.ac.id, ${ }^{2}$ gilang@ub.ac.id, ${ }^{3}$ kasyful@ub.ac.id
}

(Naskah masuk: 27 Januari 2017, diterima untuk diterbitkan: 11 Maret 2017)

\begin{abstract}
Abstrak
Sistem database merupakan bagian yang tak terpisahkan dari aplikasi berskala enterprise. Data didalamnya merupakan aset yang sangat penting, sehingga data tersebut tidak boleh rusak terlebih lagi hilang. Itulah sebabnya mengapa reliabilitas dan availabilitas sistem database menjadi hal yang sangat penting. Berbagai cara telah dikembangkan untuk meningkatkan reliabilitas dan availabilitas sebuah sistem database, salah satunya adalah teknik replikasi. MariaDB Galera Cluster adalah salah satu DBMS open source populer yang memiliki mekanisme replikasi. MariaDB Galera Cluster memiliki beberapa metode State Snapshot Transfer (SST) pada saat proses replikasi, yaitu rsync, mysqldump, xtrabackup, xtrabackup-v2. Kurangnya pemahaman administrator sistem terhadap perilaku tiap metode SST dapat mengakibatkan error pada sistem database. Untuk mencegahnya diperlukan analisis yang mendalam tentang dampak dan perilaku metode SST yang digunakan. Penelitian ini fokus pada analisis kinerja dari metode SST jenis rsync. Rsync dipilih karena metode ini merupakan metode SST default yang digunakan oleh MariaDB Galera Cluster. Dari hasil percobaan disimpulkan bahwa jumlah node dalam klaster menjadi hal yang perlu menjadi perhatian. Klaster yang hanya memiliki dua node akan sangat rentan terkena gangguan jika salah satu node terputus koneksinya atau mengalami down atau crash, sehingga jumlah node minimal dalam satu klaster yang disarankan adalah tiga node agar availabilitas dan reliabilitas MariaDB Galera Cluster dapat terjaga dengan baik.
\end{abstract}

Kata kunci: database, klaster, availabilitas, reliabilitas, MariaDB Galera Cluster

\begin{abstract}
The database system is an integral part of enterprise-scale applications. The data in it is a very important asset, so it may not be damaged or lost. That's why the reliability and availability of the database system become very important. Various ways have been developed to improve the reliability and availability of a database system, one of them is a replication technique. MariaDB Galera Cluster is one of the popular opensource DBMS that has a replication mechanism. MariaDB Galera Cluster has several methods of doing Snapshot State Transfer (SST) during the replication process, namely rsync, mysqldump, xtrabackup, xtrabackup-v2. Lack of understanding by the system administrator of the behavior of every SST method can lead to errors in the database system. To prevent it, depth analysis of the impact and the behavior of the SST methods is required. This study focused on analyzing the performance of rsync SST method. Rsync is chosen because it is the default SST method used by MariaDB Galera Cluster. The experimental results show that the number of nodes in a cluster should be concerned. Clusters which only have two nodes would be highly vulnerable to disruption if one node disconnected or experience down or crash. We recommend the minimum number of nodes in a cluster is three so that the availability and reliability of MariaDB Galera Cluster can be properly maintained.
\end{abstract}

Keywords: database, cluster, availability, reliability, MariaDB Galera Cluster

\section{PENDAHULUAN}

Sistem database merupakan bagian yang tak terpisahkan dari aplikasi berskala enterprise (Domaschka et al. 2014). Hampir seluruh aplikasi pada skala enterprise memerlukan system database untuk menyimpan berbagai jenis data yang dimilikinya. Semua proses bisnis yang berjalan pada sebuah aplikasi enterprise akan membutuhkan kinerja sistem database yang optimal. Ketika database server mengalami kegagalan, maka semua layanan akan terhenti dan semua proses bisnis tidak akan dapat berjalan. Pentingnya peran database ini yang membuat sebuah database diharuskan memiliki up time yang tinggi. Data tersebut merupakan aset yang sangat penting bagi perusahaan, sehingga data tersebut tidak boleh rusak terlebih lagi hilang. Itulah sebabnya mengapa reliabilitas dan availabilitas sebuah sistem database menjadi hal yang sangat penting (Aditya \& Juhana 2015).

Berbagai cara telah dikembangkan untuk meningkatkan reliabilitas dan availabilitas dari 
sebuah sistem database, salah satunya adalah dengan teknik replikasi. Replikasi adalah teknik penggandaan data pada beberapa lokasi fisik yang berbeda untuk satu data logis yang sama (Domaschka dkk., 2014). Tujuannya agar ketika terjadi kerusakan atau kegagalan pada satu lokasi fisik maka tidak menyebabkan kegagalan keseluruhan sistem. Selain itu replikasi juga digunakan untuk meningkatkan availabilitas sistem database dengan cara membagi beban pekerjaan tiap database server. (Aditya \& Juhana 2015). Pada prakteknya implementasi teknik replikasi pada sistem database akan berbeda, tergantung pada Database Management System (DBMS) yang digunakan.

Pengimplementasian replikasi pada MariaDB dapat dilakukan dengan menggunakan MariaDB Galera Cluster. MariaDB Galera Cluster adalah perangkat lunak DBMS MariaDB yang di dalamnya telah tertanam patch MySQL-wsrep dari Codership (Yurchenko 2009). MariaDB Galera Cluster mendukung teknik multi-master database replication. Multi-master database replication memungkinkan seluruh node dalam satu klaster menjadi master database, sehingga perubahan yang terjadi pada satu node akan direplikasi ke seluruh node yang tergabung dalam klaster tersebut. Teknik ini dapat meningkatkan reliabilitas dan availabilitas dari sistem database, karena bila terjadi kerusakan atau kesalahan pada salah satu database server maka trafik akses database dapat dialihkan ke database server yang lain dalam klaster tersebut. Alasan inilah yang menyebabkan teknik multi-master database replication ini banyak digunakan pada sistem database saat ini (Aditya \& Juhana 2015).

Pada multi-master database replication dalam MariaDB Galera Cluster, ketika satu node bergabung ke dalam satu klaster (joiner node), node tersebut akan menerima pembaruan seluruh data dari salah satu node dalam klaster tersebut (donor node). Proses ini disebut dengan State Snapshot Transfer (SST). MariaDB Galera Cluster memiliki beberapa metode dalam melakukan SST, yaitu rsync, mysqldump, xtrabackup, xtrabackup-v2 (MariaDB 2017).

Tiap metode SST memiliki mekanisme yang bebeda dalam melakukan state transfer, sehingga berdampak pada perilaku database server dalam menangani kesalahan. Kurangnya pemahaman administrator sistem terhadap perilaku masingmasing metode SST dapat mengakibatkan error pada sistem database. Untuk mencegahnya diperlukan analisis yang mendalam tentang dampak dan perilaku metode SST yang digunakan. Penelitian ini fokus pada analisis kinerja dari metode SST jenis rsync. Rsync dipilih karena metode ini merupakan metode SST default yang digunakan oleh MariaDB Galera Cluster (MariaDB 2017). Hasil dari penelitian ini diharapkan dapat meningkatkan pemahaman dari administrator sistem tentang multi- master database replication yang menggunakan rsync sebagai metode SST.

Hasil penelitian ini disusun dengan struktur sebagai berikut. Bagian pertama adalah dasar teori mengenai reliabilitas, availabilitas, klaster database, jenis replikasi dan DBMS MariaDB secara umum. Bagian ini digunakan untuk menyamakan presepsi mengenai teori dan istilah-istilah yang digunakan. Bagian kedua adalah perancangan metode serta testbed yang digunakan dalam penelitian ini. Bagian ketiga adalah penjabaran hasil percobaan serta analisis dari hasil percobaan yang telah dilakukan. Bagian terakhir dari penelitian ini adalah penyampaikan kesimpulan dari keseluruhan percobaan yang telah dilakukan.

\section{DASAR TEORI}

\subsection{Availabilitas dan Reliabilitas}

Availabilitas adalah tingkat ketersediaan suatu sistem untuk diakses dan dipergunakan ketika diperlukan. Sedangkan reliabilitas adalah ukuran kemampuan suatu sistem dalam memberikan hasil yang benar ketika dipergunakan pada berbagai keadaan (Domaschka dkk., 2014). Dengan kata lain, availabilitas adalah jaminan ketersediaan layanan suatu sistem, sedangkan reliabilitas adalah jaminan kebenaran hasil pemrosesan dari suatu sistem. Secara teori, availabilitas dan reliabilitas adalah dua hal yang terbeda dan tidak terikat satu dengan yang lain. Namun pada prakteknya, availabilitas namun tanpa reliabilitas atau sebaliknya mengakibatkan sistem tersebut tidak banyak berguna (Domaschka et al. 2014). Sebagai contoh, misalnya terdapat satu sistem database dengan availabilitas tinggi namun reliabilitas rendah karena data didalamnya tidak konsisten atau sebaliknya, terdapat satu sistem database dengan reliabilitas tinggi namun availabilitas rendah karena koneksi database-nya sering terputus maka sistem database yang seperti itu menjadi tidak layak digunakan.

\subsection{Klaster Database}

Klaster database adalah kumpulan dari beberapa database server yang secara logika dapat dipandang sebagai satu kesatuan sistem database. Satu server database dalam satu klaster, atau biasa disebut sebagai node, memiliki perangkat keras (CPU, memory, disk, dll.) dan perangkat lunak (sistem operasi, service, dll.) tersediri yang bekerja secara independen. Namun secara logika, antar node dalam klaster database tersebut saling terhubung melalui sebuah perangkat lunak yang mengelola seluruh node di dalam klaster tersebut (Pacitti et al. 2005).

Klaster database merupakan salah satu solusi dalam meningkatkan availabilitas dan reliabilitas dari sebuah sistem database, karena dapat mencegah terjadinya single point of failure dari sistem 
database. Sebagian besar DBMS saat ini telah mendukung klaster database. Salah satu yang paling populer diantaranya adalah MariaDB Galera Cluster (MariaDB 2014b).

\subsection{Replikasi Synchronous dan Asynchronous}

Perbedaan utama dari replikasi synchronous dan asynchronous adalah replikasi synchronous menjamin perubahan data pada satu node akan memicu perubahan data pada node lainnya secara synchronous atau dengan kata lain terjadi secara real time, sedangkan pada replikasi asynchronous tidak menjadmin sinkronisasi data terjadi secara real time karena besarnya delay sinkronisasi data pada replikasi asynchronous bervariatif. Dampak lainnya adalah bila master node (node utama) mengalami crash maka data yang belum tersinkonisasi ke slave node (node penerima) akan hilang (MariaDB 2014b).

Secara teori, replikasi synchronous memiliki beberapa kelebihan dibandingkan dengan replikasi asynchronous, kelebihan tersebut antara lain:

- Tingkat availabilitas yang lebih tinggi;

- Transaksi pada database terjadi secara pararel di seluruh node;

- Menjamin kualitas seluruh node dalam klaster, misalnya perintah SELECT yang dijalankan sesaat setelah perintah INSERT pada node A akan menghasilkan nilai yang salah walaupun di jalankan di node-node yang lain.

Namun secara praktek, replikasi synchronous mengimplementasikan mekanisme "2-phase commit" atau distributed locking yang terbukti memiliki performa yang sangat rendah. Itulah sebabnya mengapa penggunaan replikasi asynchronous masih dominan. DBMS open source populer seperti MySQL dan PostgreSQL secara default hanya menyediakan fasilitas replikasi asynchronous (MariaDB 2014a).

\subsection{MariaDB}

MariaDB adalah DBMS yang bersifat open soruce dan dikembangkan oleh pengembang yang sama dari MySQL. MySQL sendiri merupakan DBMS yang sudah sangat populer digunakan dan saat ini telah diakuisisi oleh perusahaan Oracle. Perkembangan MariaDB terbilang sangat cepat bila dibandingkan dengan DBMS lain yang sama-sama bersifat open source. Saat ini MariaDB telah digunakan lebih dari 12 juta pengguna di dunia, termasuk perusahaan-perusahaan besar seperti booking.com, HP, Virgin Mobile and Wikipedia (MariaDB 2014b).

MariaDB Galera Cluster adalah perangkat lunak DBMS MariaDB yang di dalamnya telah tertanam patch MySQL-wsrep dari Codership (Yurchenko 2009). Patch tersebut digunakan untuk membuat sistem replikasi eksternal untuk MySQL (dan turunan yang kompatibel dengannya, termasuk
MariaDB) yang mengikuti standar API wsrep. Sistem replikasi ini nantinya dapat bersifat asynchronous atau synchronous dan dapat digunakan untuk single atau multi-master database replication (Yurchenko 2009). Pada awal perkembangannya MariaDB Galera Server merupakan package terpisah DBMS MariaDB, Namun pada versi 10.1, MariaDB Galera Server sudah terintegrasi pada DBMS MariaDB, sehingga pengguna tidak perlu lagi melakukan instalasi package MariaDB Galera Server secara manual (MariaDB 2014b)

Terdapat beberapa limitasi dalam implementasi replikasi menggunakan MariaDB Galera Server seperti yang telah dijelaskan pada laman resmi MariaDB. Limitasi tersebut dibagi ke dalam dua bagian, yaitu keterbatasan dari patch MySQL-wsrep dari Codership dan batasan yang didapatkan dari pengalaman pengguna (MariaDB 2015). Berikut ini adalah limitasi dari patch MySQL-wsrep:

- Hanya dapat bekerja pada InnoDB storage engine;

- Tidak mendukung explicit locking seperti LOCK TABLES, FLUSH TABLES \{daftar tabel\} WITH READ LOCK, (GET_LOCK(), RELEASE_LOCK ()$, \ldots)$;

- Operasi global locking seperti FLUSH TABLES WITH READ LOCK masih dapat digunakan;

- Seluruh tabel harus memiliki primary key, atau dapat juga menggunakan multi-column primary keys. Operasi DELETE tidak dapat dilakukan pada tabel yang tidak memiliki primary key;

- Query Log tidak dapat diarahkan ke dalam tabel, melainkan harus diarahkan ke sebuah file;

- Tidak mendukung XA transactions;

- Ukuran data dalam satu transaksi tidak boleh melebihi limitasi parameter wsrep_max_ws_rows dan wsrep_max_ws_size yang telah ditentukan dalam konfigurasi MariaDB Galera Cluster. Default-nya wsrep_max_ws_rows bernilai $128 \mathrm{~K}$ dan wsrep_max_ws_size bernilai $1 \mathrm{~Gb}$.

- Nilai auto-increment tidak akan berurutan karena galera memiliki mekanisme auto-increment tersendiri untuk mencegah konflik antar server;

- Bila koneksi antar node dalam klaster terputus, misalnya disebabkan karena gangguan koneksi, dan sebuah node dalam kondisi belum tersinkronisasi, maka perintah yang dijalankan pada node tersebut akan error dan menampilkan pesan error 'WSREP has not yet prepared node for application use'. Hal ini dilakukan oleh MariaDB Galera Cluster untuk mencegah terjadinya inkonsistensi data;

- Bila metode SST yang digunakan adalah rsync dan terdapat salah satu node yang mengalami crash sebelum SST berakhir maka proses rsync akan hang dan port yang digunakan akan tertahan selamanya. Pesan error 'port in use' akan ditampilkan pada error log pada server; 
- Pada klaster dengan jumlah transaksi yang tinggi, performa sistem database tidak dapat lebih tinggi dari performa node yang paling rendah dalam klaster tersebut. Hal ini disebabkan karena penggunaan wsrep provider pada MariaDB Galera Cluster akan meningkatkan jumlah transaksi dalam jumlah yang cukup besar;

- Perintah FLUSH PRIVILEGES tidak akan direplikasi sehingga pengguna harus menjalankan perintah tersebut secara manual untuk tiap node dalam klaster;

\section{PERANCANGAN}

Proses perancangan pada penelitian ini terbagi menjadi dua bagian. Bagian pertama adalah proses perancangan testbed pengujian. Bagian kedua adalah perancangan skenario pengujian.

\subsection{Rancangan Testbed}

Testbed percobaan dibangun menggunakan satu komputer fisik dan teknologi virtualisasi VirtualBox. Dalam komputer fisik tersebut akan dirancang beberapa komputer virtual dengan topologi sesuai dengan Gambar 1. Ada beberapa perangkat lunak yang digunakan dalam penelitian ini. Perangkat lunak yang tersebut adalah:

- MariaDB versi 10.1.18. Pada versi ini, MariaDB Galera cluster sudah terintegrasi di dalamnya.

- Wanem versi 3.0 yang akan digunakan untuk emulasi kondisi jaringan sesuai dengan skenario pengujian.

- VirtualBox versi 5.1.6 yang akan digunakan untuk membangun testbed penelitian.

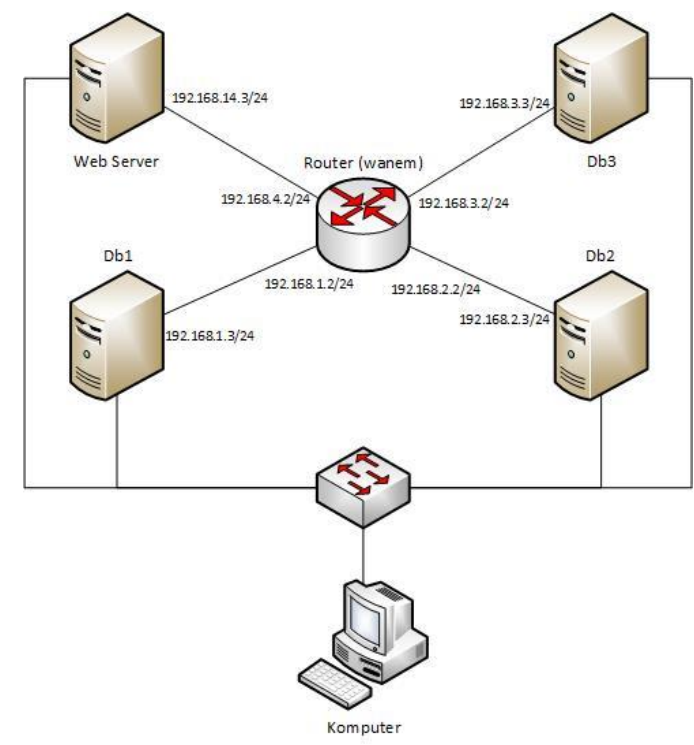

Gambar 1 Testbed Pengujian

Terdapat lima komputer virtual dalam testbed tersebut. Tiga komputer virtual berperan sebagai klaster database. Di dalamnya terdapat perangkat lunak MariaDB Galera Cluster yang telah dikonfigurasi sesusai dengan skenario pengujian.
Satu komputer berperan sebagai Web Server yang bertugas membangkitkan data yang nantinya akan dimasukkan ke dalam node tertentu dalam klaster database. Satu komputer virtual terakhir berperan sebagai router yang menghubungkan ketiga database server sekaligus melakukan emulasi trafik jaringan sesuai dengan skenario pengujian menggunakan perangkat lunak Wanem.

Keseluruhan komputer virtual tersebut terhubung ke komputer fisik (host) melalui sebuah jaringan khusus yang disebut dengan host only network. Tujuannya agar proses pemantauan tiap komputer virtual tidak terganggu oleh dampak emulasi trafik jaringan yang dilakukan oleh router.

\subsection{Rancangan Skenario Pengujian}

Bagian ini mejelaskan rancangan skenario pengujian. Dari skenario ini diharapkan dapat menghasilkan nilai pengujian yang mampu menggambarkan availabilitas dan reliabilitas dari replikasi master-to-master database server menggunakan metode SST rsync pada MariaDB Galera Cluster. Daftar skenario pengujian dapat dilihat pada Tabel 1.

Tabel 1. Skenario Pengujian

\begin{tabular}{ccc}
\hline Skenario & Jenis Kegagalan & Jumlah Node \\
\hline 1 & database service down & 2 \\
2 & database service down & 3 \\
3 & connection down & 2 \\
4 & connection down & 3 \\
5 & server down & 2 \\
6 & server down & 3 \\
7 & $10 \%$ packet loss & 2 \\
8 & $10 \%$ packet loss & 3 \\
\hline
\end{tabular}

Secara umum terdapat empat jenis kegagalan yang diuji coba, yaitu:

- database service down, yaitu kondisi dimana database service pada salah satu node sengaja dihentikan secara normal. Skenario ini mensimulasikan kondisi ketika salah satu node mengalami maintenance sehingga database service perlu dihentikan;

- connection down, yaitu kondisi dimana koneksi jaringan pada salah satu node sengaja diputus. Skenario ini mensimulasikan kondisi ketika koneksi jaringan pada salah satu database server terputus;

- server down, yaitu kondisi dimana salah satu node sengaja dimatikan paksa sehingga menyebabkan database service akan terhenti secara abnormal. Skenario ini mensimulasikan kondisi ketika perangkat keras server mengalami gangguan yang menyebabkan komputer server berhenti bekerja;

- 10\% packet loss, yaitu kondisi dimana packet loss pada koneksi jaringan salah satu node sengaja dibangkitkan sebesar $10 \%$ menggunakan network emulator. Skenario ini mensimulasikan 
kondisi ketika tejadi gangguan pada jaringan berupa packet loss.

Keempat jenis kegagalan tersebut diuji pada klaster dengan jumlah node yang berbeda, yaitu dua node dan tiga node dalam satu klaster. Tujuan dari skenario dengan perbedaan jumlah node ini adalah untuk mengetahui dampak dari penambahan jumlah node terhadap availabilitas dan reliabilitas dari klaster database.

Ketika Web Server membangkitkan data yang kemudian dimasukkan ke dalam salah satu node dalam klaster database, delapan skenario kegagalan tersebut akan dijalankan pada satu node lainnya. Kemudian dipantau dampak dari kegagalan tiap skenario tersebut. Langkah berikutnya adalah memulihkan kondisi kegagalan dan memantau kondisi klaster database setelah kondisi kegagalan tersebut behasil dipulihkan. Langkah ini mensimulasikan kondisi ketika kegagalan tersebut berhasil diperbaiki. Dengan skenario pengujian seperti ini diharapkan dapat diketahui availabilitas dan reliabilitas dari klaster database ketika dan setelah kondisi kegagalan terhadap terjadi.

\section{HASIL DAN ANALISIS PERCOBAAN}

Hasil dari percobaan sesuai dengan skenario pada Tabel 1 dapat dilihat pada Tabel 2. Data tersebut didapatkan dari beberapa kali percobaan pada tiap skenario. Hasil yang didapat tiap kali percobaan tidak berubah, sehingga dapat disimpulkan bahwa dampak dari tiap skenario kegagalan bersifat konsisten.

Skenario nomor 1 dan 2, yaitu skenario kegagalan berupa database service down dengan jumlah node 2 dan 3, tidak menyebabkan gangguan pada klaster database. Node yang aktif masih dapat melayani akses dari pengguna.

Pada skenario nomor 3, yaitu skenario kegagalan berupa network down pada salah satu node dalam klaster dengan jumlah node 2, node lain yang masih aktif tidak dapat beroperasi. Ketika mencoba memasukkan data menggunakan script yang dijalankan dari Web Server ke dalam node tersebut muncul pesan error 'Deadlock found when trying to get lock'. Hal ini disebabkan karena koneksi jaringan pada skenario tersebut terputus ketika State Snapshot Transfer (SST) sedang berlangsung pada kedua node, sehingga MariaDB mencegah adanya penambahan data baru untuk menghindari inkonsistensi data. Namun kondisi ini tidak terjadi pada klaster dengan tiga node (skenario nomor 4). Pada klaster dengan tiga node, proses SST masih dapat berlangsung pada dua node yang masih aktif, sehingga gangguan pada satu node tidak menyebabkan gangguan sinkronisasi data pada node lainnya dalam klaster tersebut. Hal ini tidak terjadi pada skenario nomor 4 yang menggunakan 3 buah node.

Pada skenario nomor 5, yaitu skenario kegagalan berupa server down pada salah satu node dalam klaster dengan jumlah node 2, node lainnya tidak mengalami gangguan dan dapat beroperasi normal. Namun ketika node yang dihentikan paksa tersebut dinyalakan kembali muncul pesan error 1407 yang bertuliskan 'WSREP has not yet prepared node for application use' pada kedua node. Error ini berlangsung terus menerus sehingga seluruh node dalam klaster berhenti bekerja dan tidak dapat melakukan sinkronisasi data. Hal ini disebabkan karena adanya data yang corrupt pada node yang dimatikan secara paksa.

Tabel 2. Hasil Percobaan

\begin{tabular}{|c|c|c|}
\hline Skenario & Dampak & $\begin{array}{c}\text { Kondisi Setelah } \\
\text { Kegagalan } \\
\text { Dipulihkan } \\
\end{array}$ \\
\hline 1 & $\begin{array}{l}\text { NORMAL; } \\
\text { Node yang lain } \\
\text { tetap dapat } \\
\text { beroperasi. }\end{array}$ & $\begin{array}{l}\text { NORMAL; } \\
\text { Replikasi kembali } \\
\text { berjalan; } \\
\text { Data sinkron. }\end{array}$ \\
\hline 2 & $\begin{array}{l}\text { NORMAL; } \\
\text { Node yang lain } \\
\text { tetap dapat } \\
\text { beroperasi. }\end{array}$ & $\begin{array}{l}\text { NORMAL; } \\
\text { Replikasi kembali } \\
\text { berjalan; } \\
\text { Data sinkron. }\end{array}$ \\
\hline 3 & $\begin{array}{l}\text { ERROR; } \\
\text { Node yang lain } \\
\text { tidak dapat } \\
\text { beroperasi. }\end{array}$ & $\begin{array}{l}\text { NORMAL; } \\
\text { Replikasi kembali } \\
\text { berjalan. }\end{array}$ \\
\hline 4 & $\begin{array}{l}\text { NORMAL; } \\
\text { Node yang lain } \\
\text { tetap dapat } \\
\text { beroperasi. }\end{array}$ & $\begin{array}{l}\text { NORMAL; } \\
\text { Replikasi kembali } \\
\text { berjalan. }\end{array}$ \\
\hline 5 & $\begin{array}{l}\text { NORMAL; } \\
\text { Node yang lain } \\
\text { tetap dapat } \\
\text { beroperasi. }\end{array}$ & $\begin{array}{l}\text { ERROR; } \\
\text { Replikasi terhenti dan } \\
\text { muncul error } 1407 \text {. }\end{array}$ \\
\hline 6 & $\begin{array}{l}\text { NORMAL; } \\
\text { Node yang lain } \\
\text { tetap dapat } \\
\text { beroperasi. }\end{array}$ & $\begin{array}{l}\text { NORMAL; } \\
\text { Replikasi sempat } \\
\text { terhenti dan muncul } \\
\text { error } 1407 \text { namun } \\
\text { tidak berapa lama } \\
\text { replikasi berjalan } \\
\text { normal kembali. }\end{array}$ \\
\hline 7 & $\begin{array}{l}\text { NORMAL; } \\
\text { Node yang lain } \\
\text { tetap dapat } \\
\text { beroperasi. }\end{array}$ & $\begin{array}{l}\text { NORMAL; } \\
\text { Replikasi kembali } \\
\text { berjalan. }\end{array}$ \\
\hline 8 & $\begin{array}{l}\text { NORMAL; } \\
\text { Node yang lain } \\
\text { tetap dapat } \\
\text { beroperasi. }\end{array}$ & $\begin{array}{l}\text { NORMAL; } \\
\text { Replikasi kembali } \\
\text { berjalan. }\end{array}$ \\
\hline
\end{tabular}

Namun sekali lagi, kondisi ini tidak terjadi pada klaster dengan tiga node (skenario nomor 6). Pada klaster dengan jumlah node 3 , pesan error 1407 tersebut hanya muncul sesaat ketika node yang dihentikan paksa tersebut dinyalakan kembali, namun setelah beberapa lama pesan error tersebut hilang dan sinkronisasi data dalam klaster tersebut dapat berjalan normal kembali.

Pada skenario nomor 7 dan 8, yaitu skenario kegagalan berupa packet loss sebesar 10\%, klaster database dapat berjalan dengan baik. Gangguan berupa packet loss sebesar $10 \%$ tersebut masih dapat 
diatasi oleh klaster database baik klaster yang menggunakan dua node maupun klaster yang menggunakan tiga node.

Terdapat beberapa catatan yang juga menjadi perhatian dari hasil percobaan. Pertama adalah kondisi service MariaDB setelah server mengalami crash atau dihentikan paksa. Ketika server dinyalakan kembali, service MariaDB tidak dapat dinyalakan. Langkah yang harus dilakukan adalah dengan melakukan recovery database dengan perintah 'mysqld --wsrep-recover'. Perintah ini akan melakukan perbaikan data yang gagal tersinkonisasi.

\section{KESIMPULAN}

Tabel 3. Kesimpulan hasil percobaan

\begin{tabular}{ccc}
\hline \multirow{2}{*}{ Jenis Kegagalan } & \multicolumn{2}{c}{ Jumlah Node } \\
\cline { 2 - 3 } & $\mathbf{2}$ & $\mathbf{3}$ \\
\hline database service down & Normal & Normal \\
\hline connection down & Error & Normal \\
\hline server down & Error & Normal \\
\hline $10 \%$ packet loss & Normal & Normal \\
\hline
\end{tabular}

Percobaan yang dilakukan terhadap MariaDB Galera Cluster pada penelitian ini semakin menguatkan pernyataan limitasi yang telah tertulis pada dokumentasi MariaDB Galera Cluster. Selain itu terdapat beberapa hal yang perlu menjadi perhatian oleh administrator sistem ketika mengimplementasikan MariaDB Galera Cluster.

Sepeti yang telah dituliskan pada Tabel 3, hal tertama pertama yang harus menjadi perhatian adalah jumlah node dalam klaster. Hasil percobaan membuktikan bahwa klaster yang hanya memiliki dua node akan sangat rentan terkena gangguan jika salah satu node terputus koneksinya atau mengalami down atau crash. Bahkan gangguan tersebut dapat menyebabkan keseluruhan klaster berhenti bekerja. Hal ini sangat fatal karena database adalah bagian krusial dari sebuah sistem atau aplikasi, dimana kegagalan database akan menyebabkan keseluruhan sistem atau aplikasi dapat terganggu. Untuk mencegah hal tersebut, jumlah node minimal yang disarankan ketika membangun klaster database adalah tiga node. Dari hasil percobaan terbukti bahwa klaster dengan 3 buah node dapat menanggai seluruh skenario kegagalan yang diujikan dan klaster database tetap dapat bekerja dengan baik. Hal kedua adalah ketika server mengalami crash, maka service MariaDB tidak dapat berjalan ketika server meyala kembali. Perlu dilakukan recovery terlebih dahulu secara manual dengan perinah 'mysqld --wsreprecover'.

Secara umum dapat disimpulkan bahwa dengan menggunakan tiga node dalam satu klaster database, availabilitas dan reliabilitas MariaDB Galera Cluster dapat terjaga dengan baik, dengan catatan bahwa tidak ada lebih dari dua node yang mengalami kegagalan pada saat yang bersamaan. Bila memang data yang disimpakan sangat krusial, maka disarankan untuk menambah jumlah node agar dapat meningkatkan availabilitas dan reliabilitas dari sistem database.

\section{DAFTAR PUSTAKA}

Aditya, B. \& JUHANA, T., 2015. A high availability (HA) MariaDB Galera Cluster across data center with optimized WRR scheduling algorithm of LVS - TUN. In 20159 th International Conference on Telecommunication Systems Services and Applications (TSSA). IEEE, hal. 1-5.

DOMASCHKA, J., HAUSER, C.B. \& ERB, B., 2014. Reliability and Availability Properties of Distributed Database Systems. In 2014 IEEE 18th International Enterprise Distributed Object Computing Conference. IEEE, hal. 226-233.

MARIADB, 2014a. About Galera Replication. Tersedia di: https://mariadb.com/kb/en/mariadb/aboutgalera-replication/ [Diakses Januari 22, 2017].

MARIADB, 2014b. About MariaDB. Tersedia di: https://mariadb.org/about/ [Diakses Januari 12, 2017].

MARIADB, 2015. MariaDB Galera Cluster - Known Limitations. Tersedia di: https://mariadb.com/kb/en/mariadb/mariadbgalera-cluster-known-limitations/ [Diakses Januari 19, 2017].

MARIADB, 2017. MariaDB Galera Cluster Configuration Variables. Tersedia di: https://mariadb.com/kb/en/mariadb/galeracluster-system-variables/.

PACITTI, E. ET AL., 2005. Preventive Replication in a Database Cluster. Distributed and Parallel Databases, 18(3), hal.223-251.

YURCHENKO, A., 2009. MySQL patches by Codership. Tersedia di: https://launchpad.net/codership-mysql [Diakses Januari 19, 2017]. 